\title{
Rats remind us what actually counts in episodic memory research
}

\section{Benjamin M. Basile*}

Section on the Neurobiology of Learning and Memory, Laboratory of Neuropsychology, National Institute of Mental Health, National Institutes of Health, Bethesda, MD, USA

${ }^{*}$ Correspondence: benjamin.basile@nih.gov

Edited by:

Michael Beran, Georgia State University, USA

Reviewed by:

Jennifer Vonk, Oakland University, USA

Bonnie Perdue, Georgia State University, USA

Keywords: episodic, semantic, source, context, rat

\section{A commentary on}

Binding of episodic memories in the rat by Crystal, J. D., and Smith, A. E. (2014). Curr. Biol. 24, 2957-2961. doi: 10.1016/j.cub.2014.10.074

Think back to lunch yesterday. You likely remember what you ate, where you sat, who you were with, what you talked about, and myriad other details combined in a cohesive memory. Now think back to lunch the day before yesterday. Though many of the details are probably the same, you likely do not have trouble discriminating between the two memories. This example highlights that episodic memories, or memories for specific experiences, contain many details bound together in cohesive representations (Tulving, 1972; Ranganath, 2010). Contrast episodic with semantic memories, or memories for facts. You may know where the cafeteria is and that sandwiches are food, but those memories are unbound to specific events.

Tulving originally defined episodic memory as encoding dated episodes and their spatial relations (1972), or "what," "when," and "where." These criteria were objective and testable. As the study of episodic memory matured, the goal posts for identifying it were repeatedly moved away from objective criteria and toward subjective ones (reviewed in Tulving, 2002). The modern definition rests heavily on concepts like autonoetic, or self-knowing, consciousness, which gives episodic memory a phenomenal "flavor of pastness" (Tulving, 1984) and a personal "warmth and intimacy" (Tulving, 2001). Consequently, researchers of human memory often rely on participants' verbal reports of whether their memory is subjectively episodic, such as in the classic remember/know paradigm (e.g., Rajaram, 1993; Gardiner, 2001). The result is that we often define episodic memory in the way Supreme Court Justice Potter Stewart famously defined obscenity: "I know it when I see it" Stewart (1964).

Subjective reports limit the questions researchers can answer. Imagine explaining the subjective feel of episodic remembering to a person who has likely never had an episodic memory due to early brain damage (Baddeley et al., 2001). Or testing whether a bee remembers a flower's location with an intimate flavor of pastness. This clash between the subjective criteria of episodic memory and the need for objective measures, especially within comparative psychology, has produced much theory-driven running in circles about what "counts" as episodic memory, but with little progress (e.g., Clayton et al., 2003; Tulving, 2005; Suddendorf and Corballis, 2007).

Fortunately, researchers of comparative psychology have made substantial empirical progress by ignoring, for now, the subjective criteria for episodic memory and instead asking how different species remember past events (Templer and Hampton, 2013b). A recent report from Crystal and Smith (2014) highlights the strength of this approach. Episodic memories are characteristically cohesive; consider the opening example. To test the degree to which rats' memories were similarly bound into cohesive episodes, Crystal and Smith tested rats' memories for foraging episodes that shared many individual features. In each episode, rats encountered several pieces of food on an eight-arm maze. If they found a piece of chocolate themselves, another piece would be in the same location later. But if they learned the chocolate's location by being placed there by the experimenter, or if they found rat chow, that location would be empty later. They engaged in two foraging episodes on identical mazes in two different rooms, which could be differentiated by global visual cues. Thus, the two foraging episodes shared many overlapping features. To earn as much chocolate as possible, rats had to remember not only which food they found, where they found it, how they learned that information, and in which room they foraged, but also bind those features together into a cohesive memory that was distinguishable from another memory with similar features.

The rats successfully remembered the foraging episodes, revisiting the replenishing chocolate more often than the non-replenishing chocolate. Importantly, they did not confuse the two similar foraging episodes. They remembered two episodes as accurately as they remembered one. They remembered episodes that shared many features as accurately as episodes that shared few features. They could even distinguish the two episodes following a week's delay, demonstrating that their memory was long-lasting, like many human episodic memories. The absence of confusion suggests the rats did not remember each foraging event as a collection of isolated features, but rather as a cohesive whole. 
This study is one of a growing number within comparative psychology, many by Crystal and colleagues, that highlight how empirically productive the field can be when it focuses on testable criteria. Clearly, there is value to knowing whether nonhumans and humans remember past events similarly. We want to know how similar we are to other species, know how cognitive processes evolved, and identify behaviorally-valid animal models for biomedical advancement. But we cannot test the subjective feeling of pastness in nonhumans. We must identify similarities and differences by focusing on those characteristics of episodic memory that are objectively testable. We know more than ever about the degree to which other species remember multiple features of events (Clayton and Dickinson, 1998; Hampton et al., 2005; Babb and Crystal, 2006), the source of information (Crystal et al., 2013), incidental information (Zentall et al., 2001; Zhou et al., 2012), the temporal order of events (Fortin et al., 2002; Templer and Hampton, 2013a), recollectively (Menzel, 1999; Fortin et al., 2004; Basile and Hampton, 2011), explicitly (Sutton and Shettleworth, 2008; Basile et al., 2015), and over long periods of time (Crystal and Babb, 2008; Martin-Ordas et al., 2013). This list is not exhaustive, but it shows that the field has amassed an impressive knowledge of how different species remember past events, revealing both similarities and differences.

Because we have made little progress in the theoretical debate about what "counts" as episodic memory, and great progress in the empirical study of how different species remember events, the field might benefit from a more explicit rejection of the very debate itself. It is easy to get caught up in the debate about what "counts" as episodic memory, and to see each new piece of evidence as weighing on one side or the other. The recent report from Crystal and Smith should remind us that we make the most progress when we ignore intractable theoretical debates and continue gathering data.

\section{ACKNOWLEDGMENTS}

I thank Emily Kathryn Brown and Victoria L. Templer for feedback on an early draft of this commentary. This work was supported by the Intramural Research
Program of the National Institute of Mental Health.

\section{REFERENCES}

Babb, S. J., and Crystal, J. D. (2006). Episodic-like memory in the rat. Curr. Biol. 16, 1317-1321. doi: 10.1016/j.cub.2006.05.025

Baddeley, A. D., Vargha-Khadem, F., and Mishkin, M. (2001). Preserved recognition in a case of developmental amnesia: implications for the acquisition of semantic memory? J. Cogn. Neurosci. 13, 357-369. doi: 10.1162/08989290151137403

Basile, B. M., and Hampton, R. R. (2011). Monkeys recall and reproduce simple shapes from memory. Curr. Biol. 21, 774-778. doi: 10.1016/j.cub.2011.03.044

Basile, B. M., Schroeder, G. R., Brown, E. K., Templer, V. L., and Hampton, R. R. (2015). Evaluation of seven hypotheses for metamemory performance in rhesus monkeys. J. Exp. Psychol. Gen. 144, 85-102. doi: $10.1037 / \mathrm{xge} 0000031$

Clayton, N. S., Bussey, T. J., and Dickinson, A. (2003). Can animals recall the past and plan for the future? Nat. Rev. Neurosci. 4, 685-691. doi: 10.1038/nrn1180

Clayton, N. S., and Dickinson, A. (1998). Episodiclike memory during cache recovery by scrub jays. Nature 395, 272-274. doi: 10.1038/26216

Crystal, J. D., Alford, W. T., Zhou, W., and Hohmann, A. G. (2013). Source memory in the rat. Curr. Biol. 23, 387-391. doi: 10.1016/j.cub.2013.01.023

Crystal, J. D., and Babb, S. J. (2008). Spatial memory in rats after 25 hours. Learn. Motiv. 39, 278-284. doi: 10.1016/j.lmot.2008.03.002

Crystal, J. D., and Smith, A. E. (2014). Binding of episodic memories in the rat. Curr. Biol. 24, 2957-2961. doi: 10.1016/j.cub.2014.10.074

Fortin, N. J., Agster, K. L., and Eichenbaum, H. B. (2002). Critical role of the hippocampus in memory for sequences of events. Nat. Neurosci. 5, 458-462. doi: 10.1038/nn834

Fortin, N. J., Wright, S. P., and Eichenbaum, H. (2004). Recollection-like memory retrieval in rats is dependent on the hippocampus. Nature 431, 188-191. doi: 10.1038/nature02853

Gardiner, J. M. (2001). Episodic memory and autonoetic consciousness: a first-person approach. Philos. Trans. R. Soc. B Biol. Sci. 356, 1351-1361. doi: 10.1098/rstb.2001.0955

Hampton, R. R., Hampstead, B. M., and Murray, E. A. (2005). Rhesus monkeys (Macaca mulatta) demonstrate robust memory for what and where, but not when, in an open-field test of memory. Learn. Motiv. 36, 245-259. doi: 10.1016/j.lmot.2005.02.004

Martin-Ordas, G., Berntsen, D., and Call, J. (2013). Memory for distant past events in chimpanzees and orangutans. Curr. Biol. 23, 1438-1441. doi: 10.1016/j.cub.2013.06.017

Menzel, C. R. (1999). Unprompted recall and reporting of hidden objects by a chimpanzee (Pan troglodytes) after extended delays. J. Comp. Psychol. 113, 426-434. doi: 10.1037/0735-7036. 113.4.426

Rajaram, S. (1993). Remembering and knowing - 2 means of access to the personal past. Mem. Cognit. 21, 89-102. doi: 10.3758/BF03211168

Ranganath, C. (2010). Binding items and contexts: the cognitive neuroscience of episodic mem- ory. Curr. Dir. Psychol. Sci. 19, 131-137. doi: 10.1177/0963721410368805

Stewart, P. (1964). Jacobellis v Ohio. US Rep 378, 184. Suddendorf, T., and Corballis, M. C. (2007). The evolution of foresight: what is mental time travel, and is it unique to humans? Behav. Brain Sci. 30, 299-313. doi: 10.1017/S0140525X07001975

Sutton, J. E., and Shettleworth, S. J. (2008). Memory without awareness: pigeons do not show metamemory in delayed matching to sample. J. Exp. Psychol. Anim. Behav. Process. 34, 266-282. doi: 10.1037/0097-7403.34.2.266

Templer, V. L., and Hampton, R. R. (2013a). Cognitive mechanisms of memory for order in rhesus monkeys (Macaca mulatta). Hippocampus 23, 193-201. doi: 10.1002/hipo.22082

Templer, V. L., and Hampton, R. R. (2013b). Episodic memory in nonhuman animals. Curr. Biol. 23, R801-R806. doi: 10.1016/j.cub.2013.07.016

Tulving, E. (1972). "Episodic and semantic memory," in Organisation of Memory, eds E. Tulving and W. Donaldson (San Diego, CA: Academic Press), 381-403.

Tulving, E. (1984). Precis of elements of episodic memory. Behav. Brain Sci. 7, 223-238. doi: 10.1017/S0140525X0004440X

Tulving, E. (2001). "The origin of autonoesis in episodic memory," The Nature of Remembering: Essays in Honor of Robert G. Crowder, eds H. L. Roediger III, J. S. Nairne, I. Neath, and A. M. Surprenant (Washington, DC: American Psychological Association), 17-34.

Tulving, E. (2002). EPISODIC MEMORY: from mind to brain. Annu. Rev. Psychol. 53, 1-25. doi: 10.1146/annurev.psych.53.100901.135114

Tulving, E. (2005). "Episodic memory and autonoesis: Uniquely human," in The Missing Link in Cognition: Origins of Self-Reflective Consciousness, eds H. Terrace and J. Metcalfe (New York, NY: Oxford University Press), 3-56. doi 10.1093/acprof:oso/9780195161564.003.0001

Zentall, T. R., Clement, T. S., Bhatt, R. S., and Allen, J. (2001). Episodic-like memory in pigeons. Psychon. Bull. Rev. 8, 685-690. doi: 10.3758/BF03196204

Zhou, W., Hohmann, A. G., and Crystal, J. D. (2012). Rats answer an unexpected question after incidental encoding. Curr. Biol. 22, 1149-1153. doi: 10.1016/j.cub.2012.04.040

Conflict of Interest Statement: The author declares that the research was conducted in the absence of any commercial or financial relationships that could be construed as a potential conflict of interest.

Received: 09 January 2015; accepted: 14 January 2015; published online: 04 February 2015.

Citation: Basile BM (2015) Rats remind us what actually counts in episodic memory research. Front. Psychol. 6:75. doi: 10.3389/fpsyg.2015.00075

This article was submitted to Comparative Psychology, a section of the journal Frontiers in Psychology.

Copyright (c) 2015 Basile. This is an open-access article distributed under the terms of the Creative Commons Attribution License (CC BY). The use, distribution or reproduction in other forums is permitted, provided the original author(s) or licensor are credited and that the original publication in this journal is cited, in accordance with accepted academic practice. No use, distribution or reproduction is permitted which does not comply with these terms. 